\title{
Enriqueciendo la realidad: realidad aumentada con estudiantes de Educación Social
}

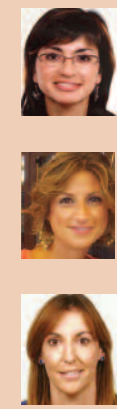

Linda Castañeda Quintero

Profesora del Departamento de Didáctica y Organización Escolar de la Universidad de Murcia

lindacq@um.es

\section{Isabel Gutiérrez Porlán}

Profesora del Departamento de Didáctica y Organización Escolar de la Universidad de Murcia

isabelgp@um.es

\section{María del Mar Román García}

Graduada en Educación Social. Miembro del Grupo de Investigación de Tecnología Educativa de la Universidad de Murcia mariamar.roman@um.es

|Fecha presentación: 04/04/2014 | Aceptación: 22/05/2014 | Publicación: 23/06/2014

\section{Resumen}

En este artículo presentamos una experiencia de innovación educativa llevada a cabo con estudiantes de $1^{\circ}$ de Grado en Educación Social en el marco de la asignatura TIC en Educación Social. Presentamos a continuación una descripción detallada de la tarea llevada a cabo, además de los principales resultados observados. Entendemos que dichos resultados inciden en la necesidad de profundizar en la importancia del aprendizaje autónomo, basado en un trabajo de aprendizaje por tareas, que entienda a los estudiantes como personas capaces de emprender tareas complejas que les lleven al desarrollo de procesos cognitivos superiores en el marco de su educación profesional.

Palabras clave: universidad, realidad aumentada, aprendizaje autónomo, aprendizaje basado en tareas

\section{Resum}

En aquest article presentem una experiència d'innovació educativa duta a terme amb estudiants de $1 r$ de Grau en Educació Social en el marc de l'assignatura TIC en Educació Social. Presentem a continuació una descripció detallada de la tasca duta a terme, a més dels principals resultats que hem obtingut. Entenem que aquests resultats incideixen en la necessitat d'aprofundir en la importància de l'aprenentatge autònom, basat en un treball d'aprenentatge per tasques, que entengui als estudiants com a persones capaces d'emprendre tasques complexes que els portin al desenvolupament de processos cognitius superiors i de gran qualitat en el marc de la seva educació.

Paraules clau: universitat, realitat augmentada, aprenentatge autònom, aprenentatge basat en tasques

\begin{abstract}
This paper presents an experience of educational innovation conducted with first year students from the degree in Social Education in the framework of the subject called ICT in Social Education. The following is a detailed description of the work carried out as well as the main results we have obtained. We believe that these results highlight the need to deepen the importance of autonomous learning, work and tasks based learning, to understand students as individuals capable of undertaking complex tasks and achieve the development of high quality higher cognitive processes and in the context of Higher Education.
\end{abstract}

Key words: higher education, augmented reality, autonomous learning, task based learning 


\section{o. Introducción}

Es posible que una de las convicciones más profundas que subyace al actual nivel de implementación de las tecnologías en la vida diaria (nivel de penetración de Internet en los hogares de nuestro país y de países del entorno y adopción de tecnologías móviles), es que es imperativo que la educación se plantee esas tecnologías como un entorno que hace parte fundamental e indiscutible del contexto vital de los estudiantes y que condiciona su relación con el conocimiento, y como herramientas para implementar y enriquecer la acción didáctica.

En este marco tecno-social que crea un entorno laboral flexible, complejo, cambiante y profundamente dependiente de las tecnologías, seguramente uno de los cambios más evidentes relativos a la educación de los profesionales para estos tiempos es la convicción de que es preciso incidir no sólo en la adquisición de conocimientos discretos, sino en el desarrollo de profesionales competentes. Se trata de formar profesionales que sean capaces de "realizar actuaciones inteligentes ante problemas complejos en un contexto" (Escudero, 2008 p. 73) y que cuenten además con unas competencias básicas que les permitan vivir en un contexto tecnológicamente rico y que cambia con una gran velocidad.

Lo anterior trae consigo la necesidad de repensar de forma crítica la aproximación del alumno a su aprendizaje, irrumpiendo con fuerza ideas como la de Entorno Personal de Aprendizaje (Castañeda y Adell, 2013), y las de aprendizaje autónomo y el aprendiz autorregulado (Boekaerts, 1997) como perspectivas básicas que deben estimularse desde los modelos educativos.

Pero además, esa realidad hace imprescindible cambios en nuestra aproximación a la tarea de enseñar, entendiendo que debemos movernos desde la perspectiva tradicional de la docencia que entiende las asignaturas como una forma de transmitir conocimiento, hasta formas más complejas y elaboradas que, desde una visión construtivista y conectivista, entiendan la función docente como una forma de crear entornos enriquecidos en los que el estudiante pueda encontrar autónomamente oportunidades valiosas para desarrollar sus competencias (Ramsden, 2003).

En la unión de esta perspectivas -si no conviccionessobre el aprendizaje y la enseñanza, hablamos de la urgencia de abordar modelos pedagógicos emergentes, o lo que es lo mismo, enfoques e ideas pedagógicas "que surgen alrededor del uso de las TIC en educación y que intentan aprovechar todo su potencial comunicativo, informacional, colaborativo, interactivo, creativo e innovador en el marco de una nueva cultura del aprendizaje" (Adell y Castañeda, 2012, p. 15).

Responden a esta definición algunos enfoques y tendencias como el aprendizaje activo y conectado (Seamless Learning), el aprendizaje basado en la indagación, el aprendizaje geolocalizado, que han sido remarcados como relevantes desde los contextos internacionales (Sharpless et al., 2013 y Johnson et al., 2014) y que abundan en la idea de expandir la experiencia de aprendizaje más allá de los límites del aula e incluso más allá de los límites de los conocimientos del profesor.

Es en estos contextos y desde estas aproximaciones, donde la Realidad Aumentada (en adelante RA) exhibe todo su potencial como tecnología maximizadora de las posibilidades de esos enfoques y de la dinamicidad de estos nuevos contextos educativos (Fundación Teléfonica, 2011; Estebanell et al., 2012, De Pedro y Martínez, 2012, Méndez, 2012, entre otros).

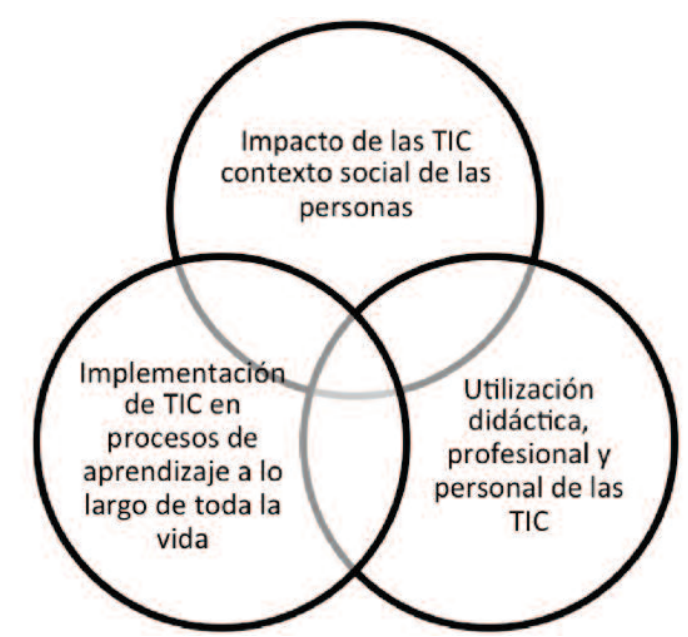

Figura 1. Ámbitos básicos de estudio en la asignatura TIC y Educación Social

Presentamos a continuación una aproximación práctica a esta realidad didáctica y social que sugerimos, en el marco de la enseñanza universitaria de los futuros profesionales de la educación social.

\section{La experiencia}

\subsection{Contexto de la experiencia}

La experiencia de trabajo que recogemos se ha llevado a cabo en el marco de la asignatura de TIC en Educación Social, asignatura cuatrimestral que se imparte en el primer curso del Grado de Educación Social. Se trata de una asignatura de formación básica y tiene una carga total de 6 créditos ECTS para el estudiante.

Esta asignatura pretende abordar la realidad de la enseñanza-aprendizaje como proceso a lo largo de toda la vida desde una doble perspectiva: la perspectiva del desarrollo tecnológico (impacto de las TIC en el contexto social de las personas) y la perspectiva pedagógica (implementación de TIC en procesos de aprendizaje a lo largo de toda la vida), haciendo además una incursión en el uso práctico de las herramientas tecnológicas (utilización didáctica, profesional y personal de las TIC), entendiendo, que si faltara alguno de estos tres componentes, el análisis de la función profesional de un Educador Social sería incompleto.

Así, entre las competencias que se entiende que un alumno debe adquirir al finalizar la asignatura se encuentran:

- Que los estudiantes puedan transmitir información, ideas, problemas y soluciones a un público tanto especializado como no especializado.

- Ser capaz de gestionar la información y el conocimiento en su ámbito disciplinar, incluyendo saber utilizar como usuario las herramientas básicas en TIC.

- Capacidad para trabajar en equipo y para relacionarse con otras personas del mismo o distinto ámbito profesional.

- Desarrollar capacidades de análisis de realidades sociales y educativas y la elaboración de proyectos de intervención en relación con diferentes contextos, sujetos y colectivos con los que trabaja la Educación Social.

- Tomar conciencia de las dimensiones organizativas y profesionales de la Educación Social, así como de sus relaciones con el entorno social, potenciando la creación de redes y servicios sociales y educativos integrados. 
- Diseñar y aplicar criterios y procedimientos para obtener información, analizar e interpretar la realidad social y educativa, así como identificar necesidades de individuos, instituciones y otros contextos de ejercicio de la profesión.

- Comprender y actuar de acuerdo con el sentido social y ético de la educación social y desarrollar las actitudes y procesos necesarios para el aprendizaje continuado a lo largo de la trayectoria profesional.

La asignatura se organizó en torno al trabajo grupal y por tareas orientadas al desarrollo por parte de los alumnos de las competencias anteriormente citadas, siendo una de estas tareas la Gymkana sobre realidad aumentada que detallamos a continuación.

\subsection{El tema a tratar: La realidad aumentada}

La historia de la RA no es tan reciente como podría parecernos, el término augmented reality es acuñado en 1992 por el ingeniero de Boeing Tom Caudell (Lee, 2012); la primera librería de realidad aumentada (ARToolkit http://www.hitl.washington.edu/artoolkit) es desarrollada por Kato en 1999 y el primer juego basado en realidad aumentada (ARQuake, Interactive Outdoor Augmented Reality Collaboration System http://wearables.unisa.edu.au/projects/arquake) fue creado por Bruce Thomas en el año 2000.

Sin embargo, la generalización de los dispositivos móviles de acceso a Internet -en concreto los smartphone y las tabletas-, su increíble penetración en el mercado de las comunicaciones personales y el extraordinario impacto en el día a día de las personas (Fundación Teléfonica, 2011), le ha dado un impulso mayor al uso de la RA y ha hecho posible su integración en una gran cantidad de sectores, como el educativo.

Decimos que bajo el paraguas del término RA se agrupa a aquellas tecnologías que permiten la superposición en tiempo real de imágenes, marcadores o información, generada virtualmente e información del mundo presencial (Fundación Teléfonica, 2011). Dichas tecnologías permiten complementar y enriquecer la información que percibimos del mundo real con elementos e información del mundo virtual (Basogain et al., 2007) de manera que sirvan como complemento mutuo de la percepción e interacción del usuario y le permitan una experiencia en "una realidad mixta en tiempo real" (De Pedro, 2011 p. 301).

Es importante no confundir la RA con la realidad virtual. Si bien ambos términos comparten algunos elementos, la realidad virtual sustituye a la real, lo que no ocurre con la RA que implica un aumento (de ahí su nombre) de la experiencia sensorial o de información en el mundo real (Basogain et al., 2007).

Así pues, se entiende que para que la RA se lleve a cabo es necesario contar al menos con cuatro elementos esenciales:

- Cámara que nos permita capturar las imágenes que vemos de la realidad. Esta cámara puede ir en cualquier tipo de dispositivo, teléfono, videoconsola, tablet.

- Pantalla sobre la que proyectar la unión de la información, tanto la real como la virtual. En caso de usar la cámara de un teléfono, videoconsola o tableta, ésta pantalla estará incorporada en el mismo dispositivo que la cámara.

- Un software o programa que se encargue de mezclar la información.
- Un mecanismo que ligue ambas informaciones -presencial y virtual-.

En cuanto a los tipos de RA, si nos basamos en el mecanismo que liga la información aumentada en la tecnología, hablamos de 2 tipos de tecnologías de RA (Estebanell et al., 2012):

- Realidad Aumentada Geolocalizada: que nos permite accede a información virtual ligada a un determinado punto en el espacio, y a la que podemos acceder normalmente a través del uso de navegadores u otras herramientas que interpretan nuestra posición en el espacio (a través de brújula y acelerómetros que suelen venir incorporados en la mayoría de los smartphones y tabletas) y nos ofrecen dicha información.

- Realidad Aumentada basada en imágenes: que es aquella a la que accedemos por la lectura de una imagen, marcador específico o un código QR reconocible, por parte de un navegador o aplicación específica.

Ya en el año 2010 el Informe Horizon (Johnson et al, 2010) auguró que la RA sería una de las tecnologías del futuro y desde entonces son muchos los proyectos y experiencias educativas que se han desarrollado en torno a esta. A día de hoy ya hay numerosas experiencias de realidad aumentada en el contexto educativo (muestra de ellas pueden ser revisadas en el proyecto Aumenta.me http://www.aumenta.me de la fundación Espiral http://ciberespiral.org), desde las experiencias más sencillas basadas en la incorporación de códigos QR ligados a información en la red a los entornos físicos para ampliar la experiencia (adosarlos a elementos de una exposición, a edificios escolares, etc.), pasando por las búsquedas de contenido meramente visual a través de buscadores visuales como las Goggles de Google o el buscador Aumentaty (http://visualsearch.aumentaty.com) y por las herramientas que permiten la experiencia de realidad aumentada en 3D (el caso de ColAR Mix), hasta la incorporación de los navegadores de realidad aumentada como Aurasma (http://www.aurasma.com), Junaio (http://www.junaio.com), Layar (https://www.layar.com) o Wikitude (http://www.wikitude.com) en actividades más complejas.

\subsection{Características de la tarea}

La experiencia de trabajo con los alumnos se realizó de forma grupal, como todas las tareas que se realizaron en esta asignatura. Los alumnos trabajan de forma autónoma en el marco de cada uno de sus grupos, explorando y analizando la información para alcanzar cada uno de los resultados propuestos.

\begin{tabular}{|l|l|}
\hline Patrimonio árabe en Murcia & Teatros de hoy y ayer \\
\hline $\begin{array}{l}\text { ONGs y acción social en } \\
\text { Murcia }\end{array}$ & $\begin{array}{l}\text { Barracas y fiestas } \\
\text { tradicionales de Murcia }\end{array}$ \\
\hline Alfonso X El Sabio & Guía turística de Murcia \\
\hline Semana Santa en Murcia & La Universidad de Murcia \\
\hline $\begin{array}{l}\text { Museos de la ciudad y obras } \\
\text { de arte }\end{array}$ & $\begin{array}{l}\text { Principales vías y puntos de } \\
\text { comunicación en la ciudad }\end{array}$ \\
\hline
\end{tabular}

Tabla 1. Temas trabajados en las Gymkanas. 
Para esta tarea, cada uno de los grupos debía programar una caza del tesoro educativa centrada en un tema de los 10 que se especifican en la Tabla 1, según el reparto realizado en el aula.

Los grupos de trabajo participaban en la tarea desde dos perspectivas diferentes, por una parte como creadores de la gymkana en torno al tema que les había tocado y por otra parte, como participantes y evaluadores de una de las gymkanas elaboradas por otro de los grupos de clase.

Para cada uno de los temas la caza del tesoro debía recorrer, con ayuda de una capa de RA en un navegador específico, los 10 puntos de la ciudad más representativos de ese tema. En cada punto los participantes encontrarían pistas que les llevarían, además de a un mejor conocimiento de ese tema relacionado con nuestra ciudad, a una pista para conseguir un tesoro final.

Una capa de realidad aumentada es la representación gráfica de una base de datos en la que se incluya información específica y se ligue a una situación geoespacial concreta (a cada uno de los puntos geolocalizados con información anexa se le llama Point of Interest POI). Para hacer y diseñar esa capa es imprescindible contar con un servidor que mantenga dicha base de datos y que sea capaz de enviarla a un navegador específico de RA. En el momento de realización de esta actividad, el único servicio que permitía la creación de bases de datos de POI de una forma intuitiva y gratuita (bases de datos de máximo $25 \mathrm{POI}$ ) y su compatibilidad con varios navegadores de RA era Hoppala, así que nos decantamos por ella. No obstante, para crear la capa era imprescindible un navegador que permitiera a los estudiantes la creación misma de la capa, así que tras explorar los tres navegadores más utilizados en RA en aquel momento (Junaio, Wikitude y Layar), nos decantamos por este último porque era el que más usuarios tenía y el único requisito para ser creador y publicador de capas era estar registrado. Ambas herramientas responden al criterio de gratuidad a la hora de trabajar con los estudiantes y de compatibilidad con distintos sistemas operativos como IOS y Android.

Así pues, cada grupo de alumnos debía crear una única capa de realidad aumentada en la que se alojarían todos los puntos relevantes del recorrido de la gymkana.

¿Qué debía de incluir cada uno de los puntos de interés (POIs)?:

- Información sobre lo qué es.

- Dos acciones que solo se habilitaran a menos de 50 metros de distancia (100 metros para el caso de la Catedral de Murcia).

- Un tuit programado (con el hashtag de clase y uno propio del recorrido en cuestión).

- Página web con información sobre el punto de interés.

De los 20 POIs incluidos, 10 eran puntos por los que necesariamente había que pasar para poder alcanzar la siguiente pista (POIs de recorrido) y otros 10 eran puntos con información relevante sobre dicho punto pero que no llevaban a otra pista (puntos trampa). Los puntos reales que permitían seguir con el recorrido, incluían además de la información antes mencionada una pista para el siguiente POI y una pista del tesoro, imprescindible para llegar al tesoro final (todos los recorridos debían llevar a un tesoro).

Puesto que eran necesarias dos pistas por cada uno de los POIs del recorrido, fue necesario elaborar 20 pistas que debían contemplar los siguientes requisitos:
- 10 serían vídeos subidos a Youtube y protagonizados por miembros del grupo.

- Al menos 8 Marcadores de Realidad Aumentada EZFLAR (http://www.ezflar.com/), como mínimo 5 de éstos debían ser códigos QR realizados con el codificador que cada uno quisiera (se animaba a los alumnos a buscar de forma autónoma en la red).

- Se debía incluir dentro de las pistas, alguna en la que los participantes, al llegar a ella, realizaran una actividad: bailar, cantar, o alguna acción que a cada grupo se le ocurriera.

Además de lo anterior se establecieron una serie de requisitos:

- TODAS las gymkanas debían desarrollarse en Murcia ciudad.

- La gymkana sirve para aprender cosas y por tanto los POIs debían de contener información relevante.

- El grado de dificultad de las pistas debía ser intermedio (que no llevara más de 15 minutos la resolución).

- El recorrido sugerido (el de los 10 POIs de recorrido) debía poder realizarse a pie en un máximo de 30 minutos.

Una vez preparada la gymkana cada grupo debía preparar un documento físico para el grupo en cuestión que fuera a encontrar su tesoro. Este documento debía incluir:

- Tema y título de la Ruta.

- Etiqueta o Hashtag para usar en los tuits relacionados (propio de la ruta de esta gymkana).

- Nombre de la capa en layar y forma de encontrarla.

- Nombres de las personas que actuarán de Ayuda de Juego - Game Master y forma de contacto seguro con ellas (teléfono, twitter, email).

- Un código QR con una pista que nos lleve al primer POI.

Antes de comenzar el trabajo, en clase presencial, junto con la profesora y en una sesión de 45 minutos se presentaron las dos herramientas principales con las que se trabajaría en la tarea: Layar (http://www.layar.com) y HOPPALA (http://www.hoppala-agency.com/). En esta clase se facilitaron nociones básicas -escasas-sobre las mismas, pues se entendía que la clave de la tarea radicaba también en que los alumnos fueran capaces de explorar nuevas herramientas por sí mismos (siguiendo con el planteamiento de aprendizaje tecnológico mínimamente invasivo de Mitra y Rana, 2001) y sobretodo, en no hacer mucho énfasis en las tecnologías como objeto de estudio, sino en los aspectos educativos de la propia tarea.

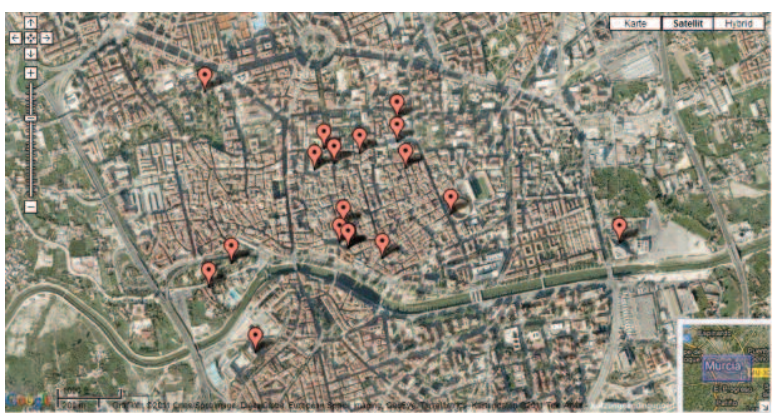

Figura 2. POIS en HOPPALLA del grupo 2. 
Castañera Quintero, Linda et al. (2014). Enriqueciendo la realidad: realidad aumentada con estudiantes de Educación Social

\begin{tabular}{|c|c|c|c|c|c|c|c|c|}
\hline Criterio/Calificación & 1 & \multicolumn{2}{|l|}{2} & \multicolumn{2}{|c|}{3} & \multicolumn{2}{|c|}{4} & 5 \\
\hline POls & $\begin{array}{l}\text { No había ni } 10 \text { POIs de recorrido } \\
\text { completos. }\end{array}$ & \multicolumn{2}{|c|}{$\begin{array}{l}\text { Habia } 10 \text { POis de recorrido, pero } \\
\text { los otros } 10 \text { no estaban } \\
\text { completos. }\end{array}$} & \multicolumn{2}{|c|}{$\begin{array}{l}\text { Habia } 10 \text { POls de recorrido y } 10 \\
\text { más, completos. Era evidente } \\
\text { cuáles eran de recorrido ycuáles } \\
\text { no. }\end{array}$} & \multicolumn{2}{|c|}{$\begin{array}{l}\text { Habia } 10 \text { POls de recorrido y } 10 \\
\text { més, completos. Algunos } \\
\text { pareciande relleno, pero otros } \\
\text { no. }\end{array}$} & $\begin{array}{l}\text { Habia } 10 \text { POis de recorrido y } 10 \\
\text { más, completos. Todos parecian } \\
\text { similares a primera vista. }\end{array}$ \\
\hline Las pistas & $\begin{array}{l}\text { En realidad no habia pistas, eran } \\
\text { indicaciones de dónde seguir, } \\
\text { pero no habia nada qué resolver. }\end{array}$ & \multicolumn{2}{|c|}{$\begin{array}{l}\text { Habia al gunas pistas, pero en } \\
\text { general solo te indicaban dónde } \\
\text { seguir yya. }\end{array}$} & \multicolumn{2}{|c|}{$\begin{array}{l}\text { Todas eran pistas, aunque todas } \\
\text { demasiado sencillas. }\end{array}$} & \multicolumn{2}{|c|}{$\begin{array}{l}\text { Habia algunas pistas interesantes } \\
\text { Intercaladas con pistas } \\
\text { demasiado sencillas. }\end{array}$} & $\begin{array}{l}\text { Todas las pistas usadas requerian } \\
\text { un trabajo de analilisis, eran MUY } \\
\text { interesantes. }\end{array}$ \\
\hline $\begin{array}{r}\text { Formatos usados en las } \\
\text { pistas (videos, fotos, textos, } \\
\text { etc.) }\end{array}$ & $\begin{array}{l}\text { Estaban hechos a la carrera, sin } \\
\text { nada de reflexión, mostraban } \\
\text { descuido. }\end{array}$ & \multicolumn{2}{|c|}{$\begin{array}{l}\text { Estaban hechos sin ninguna } \\
\text { reflexióny no agregaban valor a } \\
\text { las pistas o al sitio en el que se } \\
\text { incluian. }\end{array}$} & \multicolumn{2}{|c|}{$\begin{array}{l}\text { Estaban bien, eran adecuados, } \\
\text { estaban hechos con interés para } \\
\text { las pistas. }\end{array}$} & \multicolumn{2}{|c|}{$\begin{array}{l}\text { Estaban bien resueltos, cada } \\
\text { parte ayudaba a enriquecer la } \\
\text { pista en la que se enmarcaba. }\end{array}$} & $\begin{array}{l}\text { Erancreativos, pertinentes, } \\
\text { interesantes y divertidos. }\end{array}$ \\
\hline Gramática & $\begin{array}{l}\text { En casi todos los textos es dificil } \\
\text { entender lo que queren decir. }\end{array}$ & \multicolumn{2}{|c|}{$\begin{array}{l}\text { En algunos sitios no se entiende } \\
\text { loque quieren decir. }\end{array}$} & \multicolumn{2}{|c|}{ Se entiende lo que quieren decir. } & \multicolumn{2}{|c|}{$\begin{array}{l}\text { Se usa una prosa cuidada y de } \\
\text { fácil lectura. }\end{array}$} & $\begin{array}{l}\text { La redacción de los textos es de } \\
\text { fácill lectura y muy amena. }\end{array}$ \\
\hline Ortografia & $\begin{array}{l}\text { Hay más de tres errores } \\
\text { ortográflicos. }\end{array}$ & \multicolumn{2}{|c|}{ Hay algúnerror. } & \multicolumn{2}{|c|}{ No hay errores ortográficos, } & & & \\
\hline Fotos/imágenes fijas & \multicolumn{2}{|c|}{$\begin{array}{l}\text { Se nota que muchas de las imágenes } \\
\text { usadas son pegadas del navegador y que } \\
\text { no tienen derechos. }\end{array}$} & \multicolumn{2}{|c|}{$\begin{array}{l}\text { Algunas de las imágenes usadas no tienen } \\
\text { licencia de uso }\end{array}$} & \multicolumn{2}{|c|}{$\begin{array}{l}\text { Todas las imágenes utilizadas tienen } \\
\text { licencia oes evidente que son propias. }\end{array}$} & \multicolumn{2}{|c|}{$\begin{array}{l}\text { Las imágenes que no son propias del grupo } \\
\text { estáncorrectamente citadas en algün } \\
\text { lugar de la Gymkana /Caza del tesora. }\end{array}$} \\
\hline $\begin{array}{r}\text { Pertinencia de las pistas de } \\
\text { la Gymkana/Caza del } \\
\text { tesoro }\end{array}$ & $\begin{array}{l}\text { No tienen nada que ver el tema } \\
\text { de la Gymkana/Caza del tesoro } \\
\text { conlas pistas }\end{array}$ & \multicolumn{2}{|c|}{$\begin{array}{l}\text { Algunas pistas son de relleno y } \\
\text { no se les ve la relacióncon el } \\
\text { tema de la Gymkana/Caza del } \\
\text { tesoro }\end{array}$} & \multicolumn{2}{|c|}{$\begin{array}{l}\text { Todas las pistas tienen que ver } \\
\text { con el tema inicial de la } \\
\text { Gymkana/Caza del tesoro }\end{array}$} & \multicolumn{2}{|c|}{$\begin{array}{l}\text { Las pistas tienen que ver con el } \\
\text { tema y además son importantes } \\
\text { para descubrir el tesoro }\end{array}$} & $\begin{array}{l}\text { Todas las pistas están muy } \\
\text { relacionadas con el tema y sin } \\
\text { todas ellas es muy dificil } \\
\text { descubrir el tesoro }\end{array}$ \\
\hline $\begin{array}{r}\text { El contenido trabajado en } \\
\text { la Gymkana/Caza del } \\
\text { tesoro }\end{array}$ & $\begin{array}{l}\text { Aunque el tema puede ser } \\
\text { interesante, la forma en la que } \\
\text { está hecha la Gymkana/Caza del } \\
\text { tesoro, lo hace poco atractivo. }\end{array}$ & \multicolumn{2}{|c|}{$\begin{array}{l}\text { La forma en que está hecha la } \\
\text { Gymkana/Caza del tesoro hace } \\
\text { que no sea evidente el interés del } \\
\text { tema que se trata. }\end{array}$} & \multicolumn{2}{|c|}{$\begin{array}{l}\text { La forma de trabajar el tema por } \\
\text { parte de los elaboradores de la } \\
\text { Gymkana/Caza del tesoro ha } \\
\text { hecho de este un tema } \\
\text { interesante para explorar en } \\
\text { Murcia. }\end{array}$} & \multicolumn{2}{|c|}{$\begin{array}{l}\text { No pensâbamos que nos fuera a } \\
\text { interesar el tema, pero la forma } \\
\text { enla que está abordado en la } \\
\text { Gymkana/Caza del tesoro lo } \\
\text { hacen interesante. }\end{array}$} & $\begin{array}{l}\text { La Gymkana/Caza del tesoro es } \\
\text { interesante y el tema termina } \\
\text { siendo apasionante. Debería } \\
\text { proponerse a Layar como Ruta } \\
\text { permanente. }\end{array}$ \\
\hline Nivel de Aprendizaje & $\begin{array}{l}\text { No hemos aprendido nada del } \\
\text { tema encuestión ni de la forma } \\
\text { en la que se aborda. }\end{array}$ & \multicolumn{2}{|c|}{$\begin{array}{l}\text { No hemos aprendido nada del } \\
\text { tema en cuestión ni de la forma } \\
\text { en la que se aborda. }\end{array}$} & \multicolumn{2}{|c|}{$\begin{array}{l}\text { Hemos aprendido algunas cosas } \\
\text { del tema en cuestión }\end{array}$} & \multicolumn{2}{|c|}{$\begin{array}{l}\text { Ha sido un continuo aprendizaje } \\
\text { de cosas (aunque fuesen } \\
\text { pequeñas) del tema tratado }\end{array}$} & $\begin{array}{l}\text { La Gymkana/Caza del tesoro te } \\
\text { hace descubrir cosas que a } \\
\text { simple vista no son evidentes, al } \\
\text { final todos sebemos un poco más } \\
\text { sobre el tema tratado }\end{array}$ \\
\hline $\begin{array}{r}\text { Nivel de diversión en la } \\
\text { Gymkana/Caza del tesoro }\end{array}$ & Muy aburrida & \multicolumn{2}{|c|}{ Aburrida } & \multicolumn{2}{|c|}{ Algunos momentos divertidos } & \multicolumn{2}{|l|}{ Ha sido divertida } & No hemos divertido muchisimo \\
\hline $\begin{array}{l}\text { Papel del game-master (las } \\
\text { estrellas del otro equipo) }\end{array}$ & $\begin{array}{l}\text { No hubo forma de contactar con } \\
\text { ellas. Aunque las necesitamos no } \\
\text { aparecieron en ningún } \\
\text { momento. }\end{array}$ & \multicolumn{2}{|c|}{$\begin{array}{l}\text { No contactamos con ellas, no las } \\
\text { necesitamos pero tampoco nos } \\
\text { ofrecieron nada, ni ayuda, ni } \\
\text { nada. }\end{array}$} & \multicolumn{2}{|c|}{$\begin{array}{l}\text { Estuvieron a disposición los } \\
\text { primeros dias, no las necesitamos } \\
\text { vellas tampoco ofrecieron nada. }\end{array}$} & \multicolumn{2}{|c|}{$\begin{array}{l}\text { Estuvieron a disposición todo el } \\
\text { tiempo y se pusieron en contacto } \\
\text { connosotros varias veces por si } \\
\text { necesitábamos algo. }\end{array}$} & $\begin{array}{l}\text { Estuvieron muy pendientes de } \\
\text { nosotros, nos animaban, nos } \\
\text { ayudaban, fueron compan̂ia } \\
\text { durante toda la Gymkana/Caza } \\
\text { del tesoro. }\end{array}$ \\
\hline
\end{tabular}

Figura 3. Rúbrica de evaluación por grupos

Una vez las Gymkanas fueron programadas por los estudiantes, en clase presencial, se procedió a la revisión de cada una de ellas y se repartieron entre los diferentes grupos para llevarlas a cabo. Cada uno de los grupos debía establecer un día para realizar la gymkana dentro de un plazo establecido, lo que suponía también concretar una fecha con la persona del grupo creador, que actuaría como "Ayuda de Juego" síncrona.

Para evitar posibles problemas de tipo más técnico se advirtió a los grupos que comprobaran que podían acceder y ver la capa de información en Layar y se aconsejó que en caso de no poder entrar, se pidiera al grupo su usuario y contraseña para acceder en layar a la capa como desarrolladores.

Durante la resolución de la gymkana los grupos debían realizar un seguimiento pormenorizado de la misma (fotos, videos, historias, anécdotas, etc.), y ese seguimiento se debía plasmar posteriormente en el blog del grupo.

Como mencionamos anteriormente, además de completar el recorrido, los grupos debían actuar como evaluadores del mismo. Para poder completar esta evaluación se facilitó la rúbrica de la Figura 3 con los diferentes apartados evaluables a tener en cuenta.

\section{Algunos datos de la experiencia}

Para conocer algunos de los aspectos más destacados de la experiencia llevada a cabo los alumnos completaron dos cuestionarios, un cuestionario inicial justo antes de comenzar la experiencia y un cuestionario final una vez que se completó la experiencia de trabajo. El objetivo principal del cuestionario inicial fue conocer mejor algunas características del grupo en relación con la tarea planteada, como la disposición de teléfono inteligente y conexión de datos en el mismo, el grado de conocimiento sobre los conceptos de RA y códigos QR, un total de 6 ítems que nos permitieron conocer el punto de partida de nuestro grupo de participantes. Por otra parte, el objetivo principal del cuestionario final fue valorar el manejo de los aspectos más tecnológicos de la actividad puesta en marcha así como algunas cuestiones de organización y aprendizaje en el desarrollo de la misma.
En el siguiente apartado presentamos los resultados principales derivados de ambos cuestionarios, que nos ayudarán a tener una idea más aproximada acerca de la percepción de los alumnos sobre el trabajo realizado y sobre el proceso de aprendizaje llevado a cabo por parte del grupo.

\subsection{Características del grupo}

La experiencia se llevo a cabo con alumnos del $1^{\circ}$ de Grado de Educación Social en el marco de la asignatura TIC en Educación Social. Esta asignatura se imparte en el primer cuatrimestre y supone un total de 6 créditos ECTS para los estudiantes y 7,5 créditos ECTS para el profesorado.

Los estudiantes que realizaron esta actividad fueron un total de 109, divididos en 10 grupos de trabajo diferentes, de los que el $80 \%$ eran mujeres y el $20 \%$ hombres, con edades comprendidas entre los 18 y los 35 años de edad, siendo la media de edad de 20,68, la desviación típica ( $\sigma$ ) de 4,26 y la edad más repetida (moda) la de 19 años.

2.2 Dotación y uso de tecnología por parte de los alumnos En lo referido a la disponibilidad de teléfonos inteligentes (smartphone) por parte de los alumnos, encontramos que casi la mitad de los alumnos $(44,89 \%)$ disponía de estos terminales teniendo además un $31,68 \%$ conexión de datos móviles en dichos dispositivos (hecho que nos garantizaba que al menos en un grupo de trabajo se contaría con dispositivos con los que poder realizar la actividad).

Por otra parte nos interesó conocer el uso que hacían los alumnos de diferentes herramientas telemáticas antes de la tarea. Como se observa en la Figura 4 observamos que las herramientas más utilizadas son las redes sociales ( $91 \%$ afirma tener un perfil creado y un $72,4 \%$ se muestra muy activo en ellas), los blogs con un 42,8\% y las herramientas de publicación de vídeo con un 39,7\%. También nos encontramos con un gran número de herramientas con un uso bastante inferior como son los foros, usados solamente por un $11,2 \%$ del alumnado.

La Figura 4 nos muestra aquellas herramientas menos conocidas y utilizadas por parte del alumnado, entre las que encontramos los foros, como ya decíamos anteriormente, y las herramientas de publicación de contenidos. 


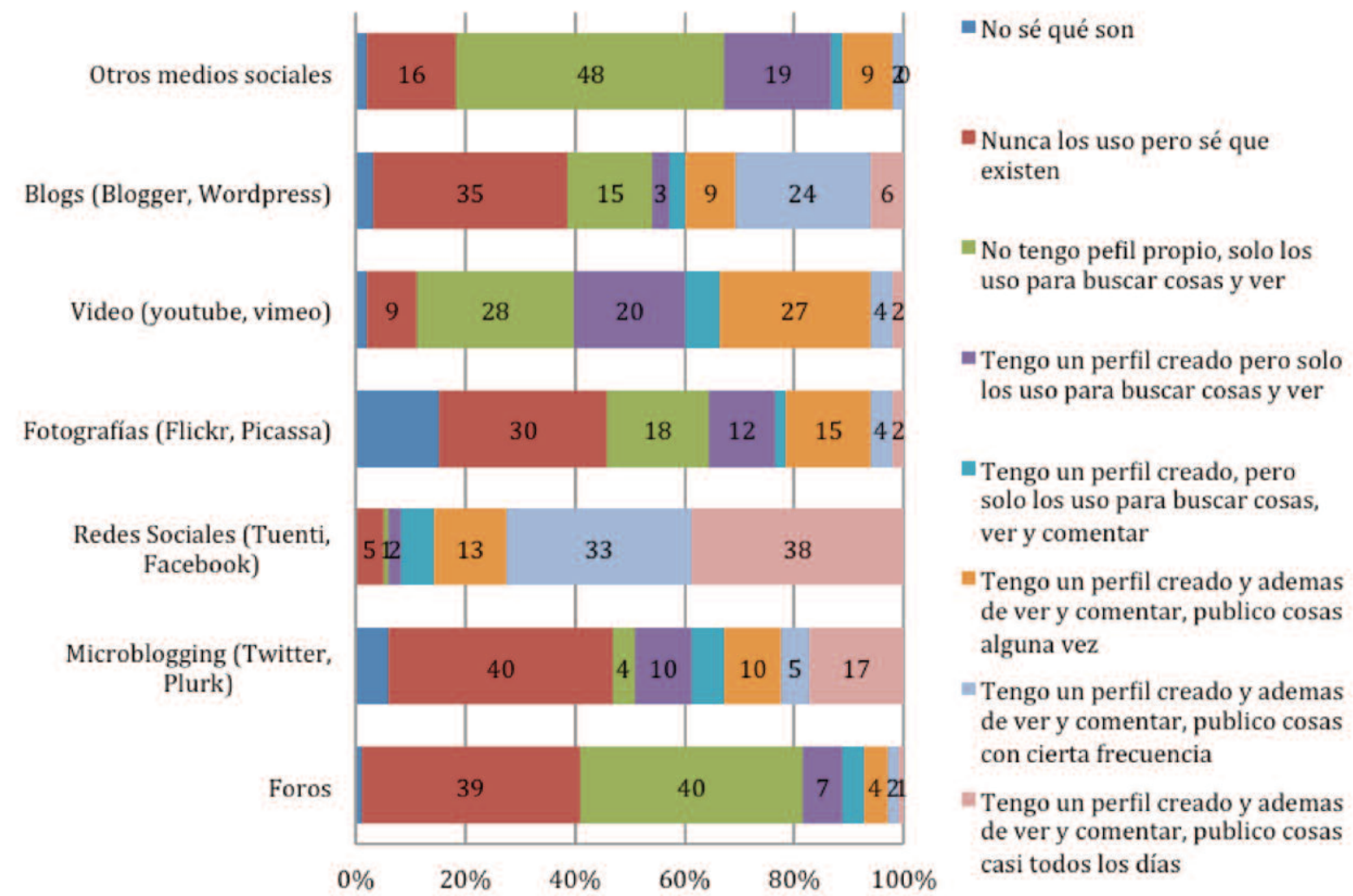

Figura 4. Conocimiento y uso de diferentes herramientas telemáticas por parte de los alumnos.

Ante la pregunta sobre los dos conceptos más importantes con los que se iba a trabajar en el desarrollo de la actividad, RA y códigos QR, hay que destacar que la mayoría de los alumnos no conocía ninguno de los términos aunque el término de RA les era algo más familiar. Tan solo el $2 \%$ de los alumnos conocía y había usado tanto la RA como los códigos QR.

\subsection{El desarrollo de la experiencia.}

Adentrándonos en los aspectos propios de la experiencia encontramos algunos datos muy interesantes. En primer lugar se valoraba la participación de cada uno de los alumnos en las diferentes partes de la tarea planteada. Como se ha visto en la descripción de la tarea, ésta constaba de muchas partes $\mathrm{y}$ pasos en los que encontramos una serie de roles de trabajo diferenciados.

Para valorar la participación en cada una de las partes de la tarea, se pidió a los alumnos que puntuaran su impli- cación en cada una de éstas del 1 al 10. Encontramos que la mayoría de los alumnos se puntúa por encima de 7 , destacando los roles de búsqueda de información, la creación de pistas y labores de coordinación del equipo. Los ítems correspondientes a cuestiones más tecnológicas como la creación de capas en Layar, la creación de vídeos y códigos QR son los que reciben menor grado de implicación por parte de los alumnos como se puede comprobar en la Figura 6.

Sobre el nivel de dificultad detectado por los alumnos en las diferentes partes de la actividad (Figura 7), nuestros estudiantes consideran que aspectos como la búsqueda de información, la creación de códigos QR y de capas de Layar han sido las de menor dificultad, mientras que los pasos que más dificultad les ha planteado han sido la comprobación del recorrido, así lo afirman un 44,95\% de los participantes, la realización de vídeos $(40,37 \%)$ y la creación de POIs. Otro dato interesante que nos muestra esta pregunta es un alto porcentaje de participantes, en relación a los otros aparta-

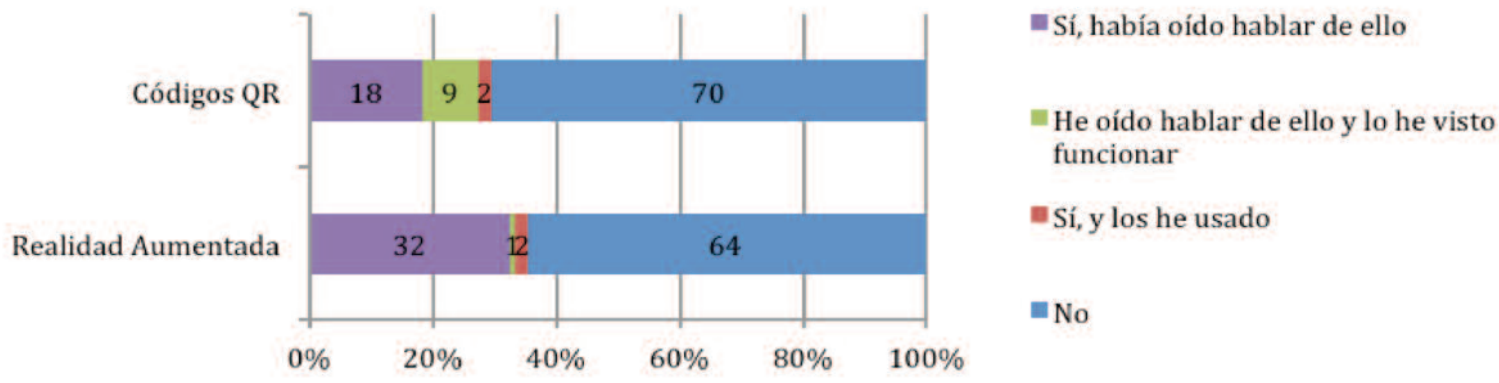

Figura 5. Conocimiento y uso de RA y códigos QR por parte de los alumnos. 


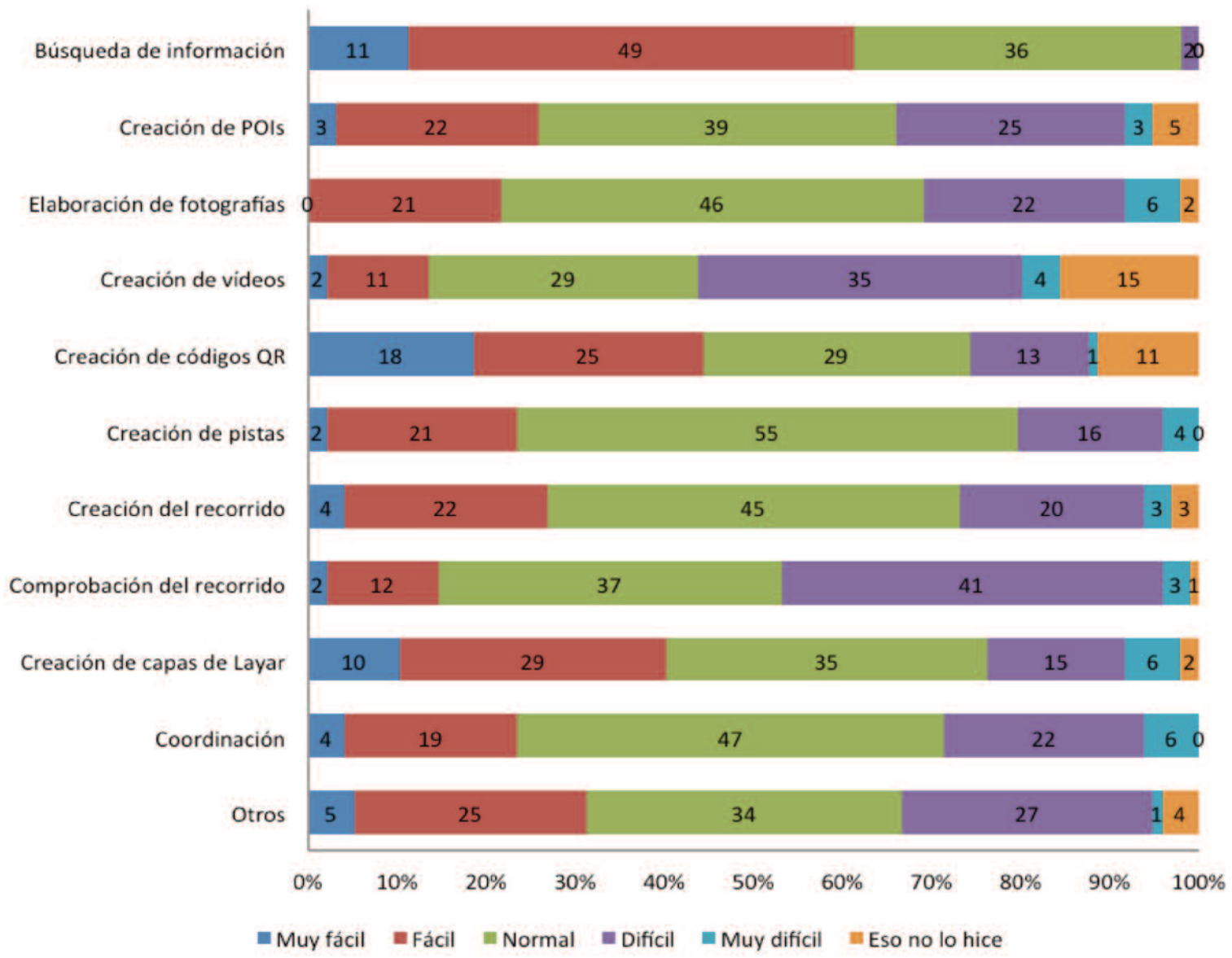

Figura 6. Estudiantes: Valoración de su propia implicación en los diferentes apartados de la tarea. Porcentajes.

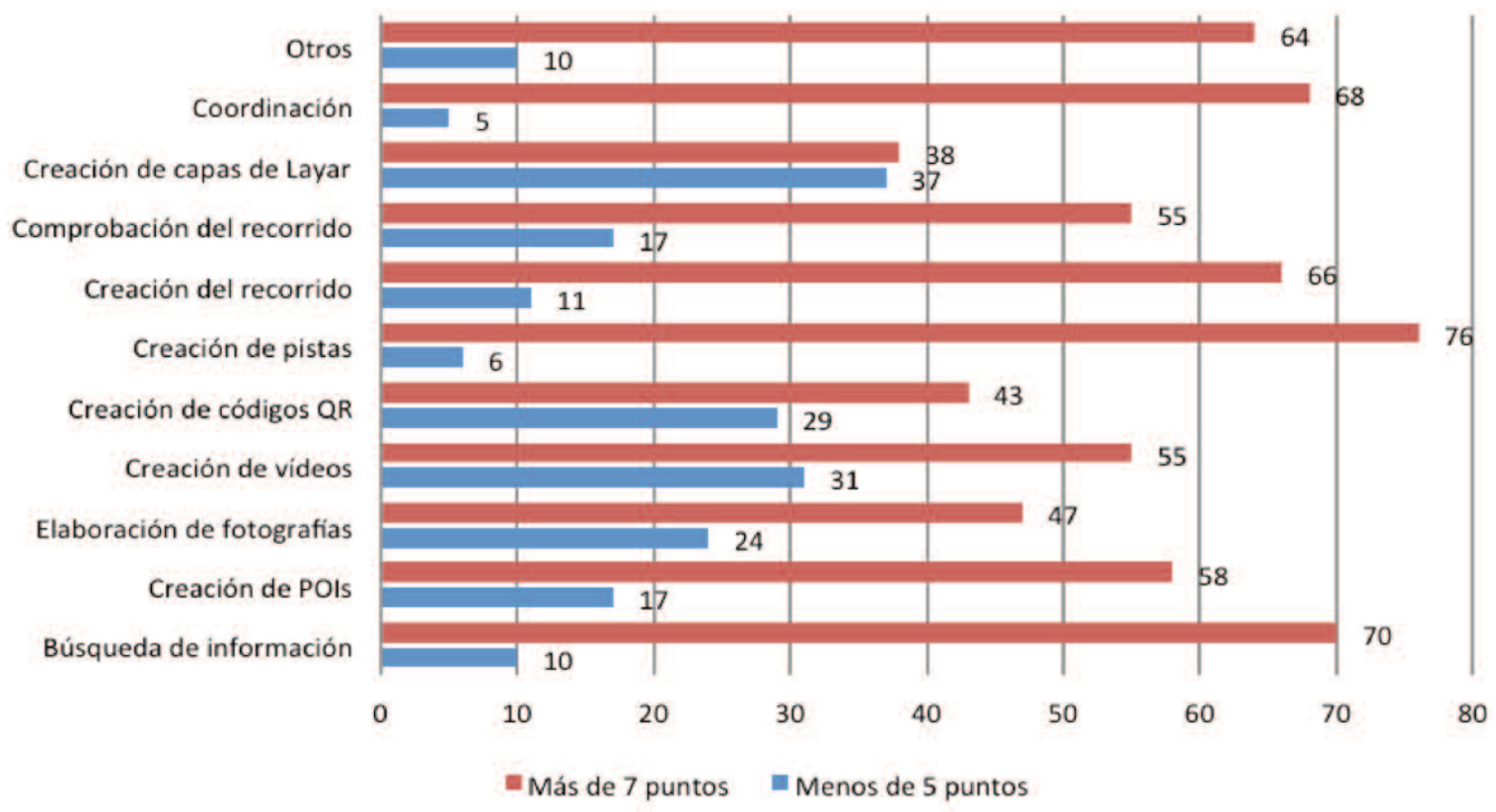

Figura 7. Nivel de dificultad percibido por los estudiantes en los diferentes apartados de la tarea. 


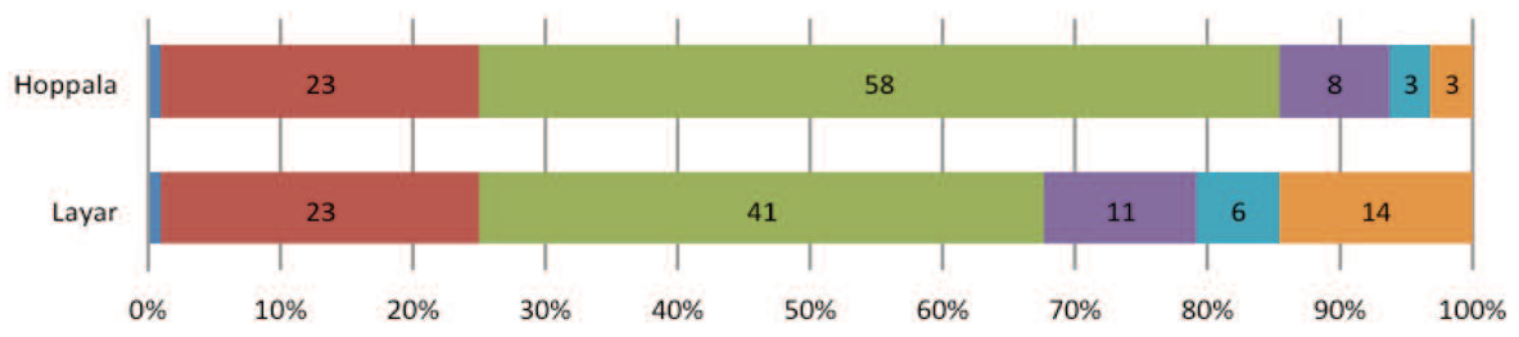

\author{
No sé de qué me hablas \\ í, sin problemas \\ = $\mathrm{Si}$, pero nos costó que funcionase, la herramienta da problemas \\ - Sí, pero nos costó que funcionase, no nos acalarábamos mucho con la herramienta \\ = No del todo, no nos aclarábamos mucho con el funcionamiento de la herramienta \\ = No, la herramienta no llegó a funcionar
}

Figura 8. Funcionamiento de las herramientas de Realidad Aumentada.

dos, que reconoce no haber participado en el apartado de realización de vídeos (casi un 16\% de estudiantes), a pesar de aparecer en el cuestionario inicial como una de las herramientas más usadas.

Las tareas que presentaban una dificultad media, desde el punto de vista de los estudiantes, son la creación de pistas, seguida por la coordinación del grupo y la creación del recorrido.

Con respecto a las herramientas propias para la realización de la RA, Layar y Hoppala, y su funcionamiento, los participantes plantearon algunos problemas de uso. Los alumnos afirman que las dos herramientas daban problemas técnicos, por lo que les costó ponerlas en marcha (41,2\% Layar y 58,7\% Hoppala). Hemos de destacar que Layar fue la herramienta que más dificultades presentó a los alumnos, para un $18,6 \%$, ya que afirmaron no "aclararse" ni con la propia herramienta ni con su funcionamiento. Por otra parte también hay que destacar que un 23,85\% de los participantes declaró que ambas herramientas no presentaron ningún problema de tipo técnico para ellos (Figura 8).

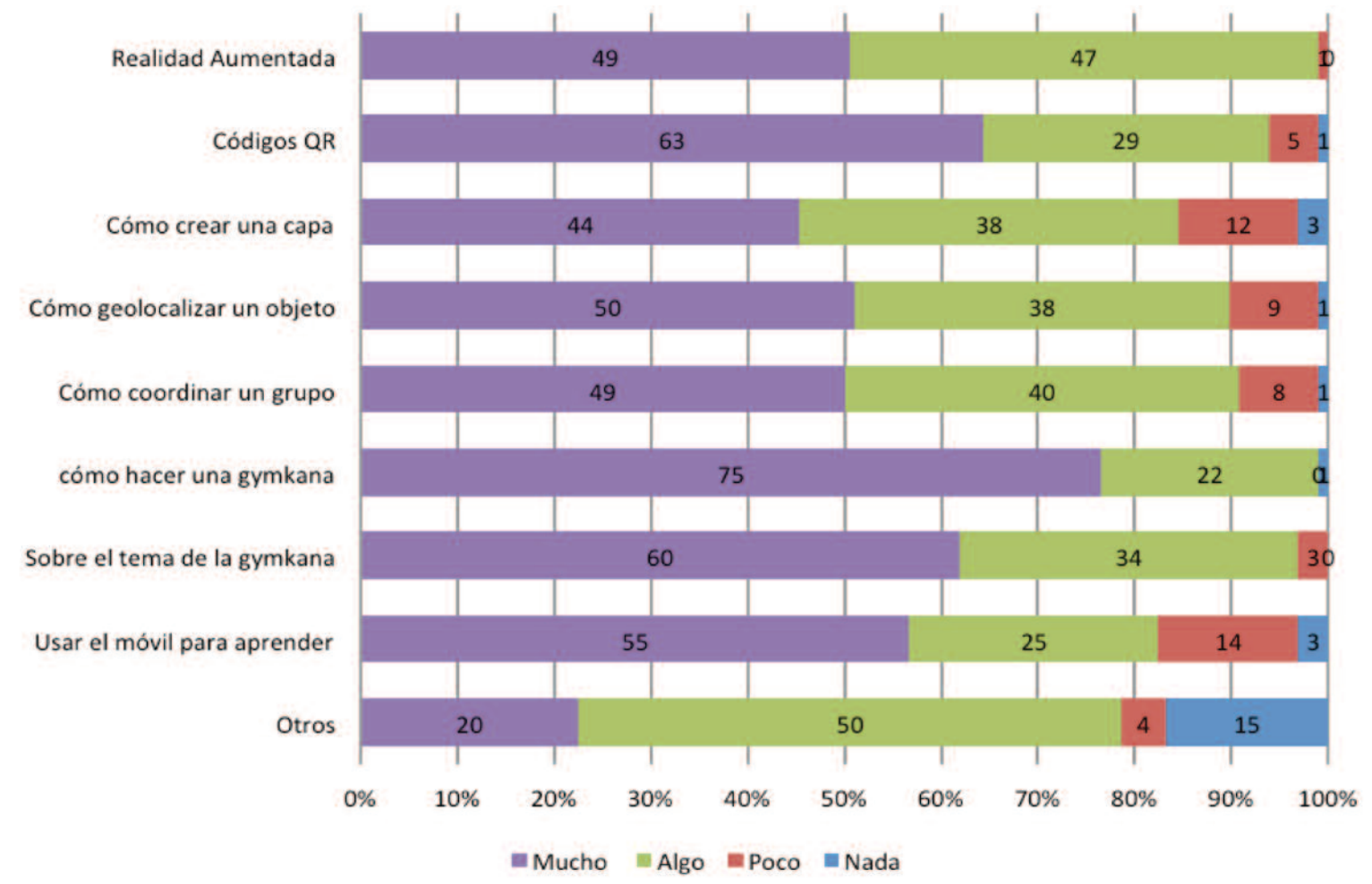

Figura 9. Grado de aprendizaje en los diferentes apartados de la tarea. 
Por otra parte, en lo que respecta a los procesos de aprendizaje de los alumnos, se les preguntó cómo calificarían lo que habían aprendido en torno a los siguientes aspectos:

- Realidad aumentada, códigos QR y cómo crear una capa de realidad aumentada.

- Geolocalización de objetos.

- Coordinación de grupos.

- Elaboración de una gymkana y sobre el tema sobre el que versa la gymkana.

- Uso del dispositivo móvil para aprender y otros aprendizajes.

Hemos encontrado que en todos los ítems planteados, la mitad de los encuestados consideran que han aprendido mucho, destacando los ítems de "cómo realizar una gymkana" con $75 \%$ de alumnos que afirma que han aprendido mucho de esta tarea, la realización de códigos QR con un $63 \%$ de los alumnos y sobre el tema del que tenían que realizar su gymkana un $60 \%$ del total.

Por el contrario los temas sobre los que menos han aprendido son: el aprendizaje a través del móvil con un 18,35\% de alumnos que afirma que ha aprendido poco o nada y la creación de capas de RA con un 16,5\% de los participantes.

Los resultados en cada uno de los ítems planteados son muy satisfactorios ya que en número de alumnos que afirma haber aprendido algo o mucho es del $81 \%$, superando con creces a aquellos que afirman haber aprendido poco o nada tal y como queda reflejado en el siguiente gráfico.

Finalmente se preguntó a los alumnos por la experiencia en general y la utilidad que encuentran a la misma. Los resultados a este respecto fueron muy satisfactorios ya que más del 90\% de los alumnos participantes estarían dispuestos a repetir la experiencia y además opinan que podrían hacer uso de la RA en futuras ocasiones, incluso en más de un $75 \%$ de los casos se consideran capaces de repetir la experiencia de forma individual.

\section{Conclusiones}

A la luz de los datos aportados por los propios participantes de esta actividad podemos extraer algunas conclusiones sobre la experiencia de aprendizaje llevada a cabo.

Partiendo de las características del grupo en relación a cuestiones de uso de diferentes herramientas de la red, en especial de las que sirven de apoyo para la realización de esta actividad, podemos afirmar que a pesar de la edad de los participantes en esta experiencia, lejos del perfil de "nativos digitales" (Prensky, 2001) especialmente dotados para el uso de las TIC, en este caso nuestros estudiantes responden a un modelo mucho más próximo a la categorización de White y LeCornu (2011) de "visitantes en la red". Lo cual se refleja en el hecho de que aunque poseen una cuenta en numerosos espacios y herramientas en red, sólo suelen utilizarlos para "observar", lo que les situaría dentro del perfil de "lurkers" (Preece et al., 2004, Ponte, 2011) caracterizados principalmente por mantener una actitud pasiva, leer y observar en diferentes espacios pero contribuyendo muy poco con opiniones o creaciones propias.

Somos conscientes del alto grado de dificultad y complejidad de la tarea. En primer lugar encontramos la dificultad tecnológica ya que la mayoría de alumnos desconocía qué era tanto RA como los códigos QR. La tarea tampoco estuvo exenta de dificultad desde el punto de vista metodológico, ya que se les exigía un papel completamente activo y proactivo que no están acostumbrados a asumir (como se puede observar en los datos obtenidos sobre su actitud en las redes sociales) y que además había que asumir en el marco de los grupos de trabajo.

Sin embargo, las tareas más relacionadas con la tecnología, como la creación de capas de RA y la creación de códigos $\mathrm{QR}$, han sido señaladas como las tareas que menor grado de dificultad presentaban, justo por detrás de la búsqueda de información, aspecto que llama la atención si atendemos a las características iniciales encontradas en el grupo con respecto al uso de este tipo de tecnologías. Por lo tanto podemos afirmar, que se trata de alumnos que han entendido, que de

\section{¿Podrías hacer esta actividad tú solo?}

\section{$74,31 \%$}

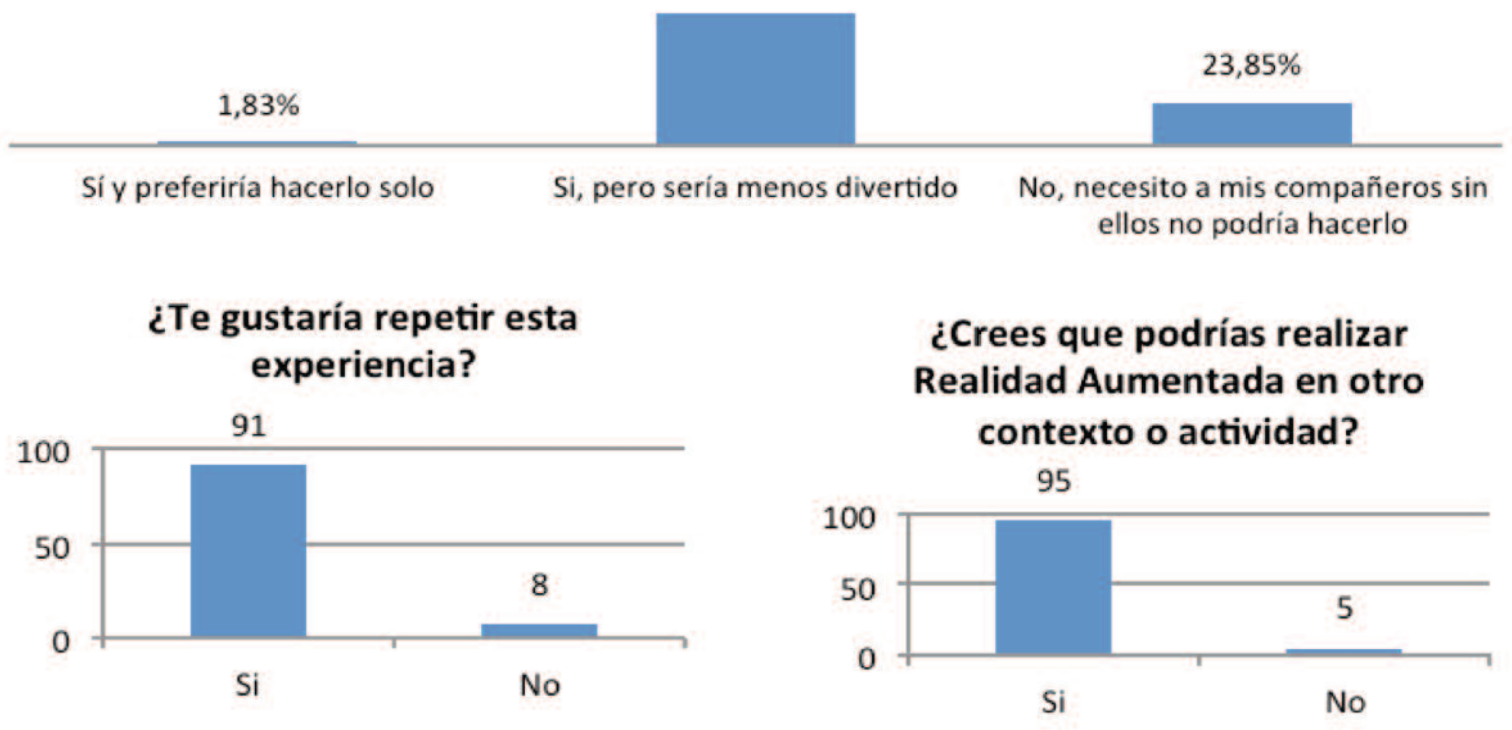

\section{¿Crees que podrías realizar} contexto o actividad?

Figuras 10, 11 y 12. Valoración general de la experiencia. 
la misma forma en que aprendieron a usar autónoma e independientemente las herramientas 2.o que usan para el ocio, pueden aprender a usar estas para desarrollar sus competencias profesionales. El reto tecnológico deja de ser tal. La herramienta no es un reto difícil y se ha integrado sin aparente dificultad en el proceso de aprendizaje.

Por su parte, la creación de vídeos sí aparece como una de las tareas que más dificultad supuso a los alumnos, algo que nos puede llamar la atención en jóvenes muy acostumbrados a tener presentes este tipo de recursos en su vida diaria. No obstante, es necesario destacar que la realización de vídeos en esta actividad no responde a un vídeo lúdico o de ocio, sino que suponía un proceso muy concreto y con unas características específicas, lo que exigió un trabajo de preproducción complejo (pensar el contenido, organizarlo y construirlo audiovisualmente, etc.) para que sea más que un simple busto parlante o para que resulte de utilidad (Bartolomé, 2008).

Aún así, llama la atención que sean precisamente las tareas más tecnológicas en las que un mayor número de participantes señala un menor grado de participación (creación de capas de RA, de códigos QR y de vídeos) aunque afirman no encontrarlas difíciles, es decir, no creen que sea difícil, pero no se suelen implicar en ellas, probablemente por esa falta de costumbre de publicar y compartir sus productos en Internet.

La autopercepción del nivel de implicación de los estudiantes, en todo caso, es muy elevada y la gran mayoría de ellos valoran su participación en cada una de las tareas por encima de 7, por lo que podemos entender que el grado de implicación con la actividad fue elevado desde el punto de vista de los alumnos.

Esta implicación refleja el planteamiento realizado desde el diseño de esta actividad. No en vano se apostó por un diseño basando en metodologías de enseñanza cuyo objetivo es el desarrollo y consecución de las competencias, trabajo activo, y uso de las TIC para crear una nueva cultura del aprendizaje focalizada en el estudiante como protagonista de la experiencia.

Esta actividad les ha permitido aprender de cada una de las acciones que debían llevar a cabo para resolver la tarea planteada y así se refleja en los resultados. De la misma forma que los datos reflejan la gran satisfacción que la tarea y lo aprendido en ella genera entre los estudiantes, y cómo -a pesar del tiempo invertido- repetirían la experiencia y entienden que es exportable a su contexto profesional real.

Este último aspecto es el que nos hace cerrar el círculo del aprendizaje, cumpliendo así con las competencias que se plantean en la asignatura. No sólo se trataba, como dice Ramsden (2003), de crear un entorno rico de experiencias y oportunidades de aprendizajes, sino de conseguir en la medida de nuestra posibilidades y limitaciones (excesiva cantidad de alumnos por clase, tutorización por parte de un único profesor, limitaciones de tiempo, etc.), emancipar a nuestros estudiantes como aprendices más independientes, autoregulados y capaces de manejar y enriquecer su propio entorno de aprendizaje.

\section{Referencias bibliográficas.}

Adell, Jordi; Castañeda, Linda (2012). Tecnologías emergentes, ¿̇pedagogías emergentes? En J. Hernández, M. Pennesi, D. Sobrino y A. Vázquez (coord.). Tendencias emergentes en educación con TIC (13-32). Barcelona: Asociación Espiral, Educación y Tecnología.
Barolomé, Antonio (2008). Vídeo Digital y Educación. Madrid: Síntesis.

Basogain, X., Olabe, M., Espinosa, K., Rouèche, C., Olabe, J. C. (2007). Realidad Aumentada en la Educación: una tecnología emergente.

http://www.anobium.es/docs/gc_fichas/doc/6CFJNS alrt.pdf Fecha de consulta, 12.06.2014.

Boekaerts, Monique (1997). Self-regulated learning: a new concept embraced by researchers, policy makers, educators, teachers, and students. Learning and instruction, 7 (2), pp. 151-86. http://dx.doi.org/10.1016/So959-4752(96)0oo15-1

Castañeda, Linda; Adell, Jordi (eds.). (2013). Entornos personales de Aprendizaje: claves para el ecosistema educativo en red. Alcoy: Marfil.

De Pedro, Javier (2011). Realidad Aumentada: un nuevo paradigma en la educación superior. En Actas del Congreso Iberoamericano Educación y Sociedad. Universidad La Serena (Chile), pp. 300-307. ISBN: 978-84-8138-017-0.

Escudero, Juan M. (2008). Las competencias profesionales y la formación universitaria: posibilidades y riesgos. Red U. Revista de Docencia Universitaria, Monográfico, 2

http://upo.es/revistas/index.php/pedagogia_social/ar ticle/viewFile/35/31 Fecha de consulta, 12.06.2014.

Estebanell, Meritxell; Ferrés, Josefina; Cornellà, Pere; Codina, David (2012). Realidad aumentada y códigos QR en educación. En Tendencias emergentes en educación con TIC (pp. 277-320). Barcelona: Editorial Espiral. ISBN 978-84-616-0448-7.

Fernández, Jorge Juan (2008): Más allá de Google. Barcelona: Zero Factory S.L.

Fundación Telefónica (2011). Realidad Aumentada: una nueva lente para ver el mundo. Ariel y Fundación Telefónica.

Johnson, Larry; Adams Becker; Samantha, Estrada, V., Freeman, A. (2014). NMC Horizon Report: 2014 Higher Education Edition. Austin, Texas: The New Media Consortium.

Lee, Kangdon (2012). Augmented Reality in Education and Training. Techtrends: Linking Research \& Practice To Improve Learning, 56 (2).

Méndez, Pedro J. (2012). Mundos Cambiantes: La Tecnología y la Educación 3.o. Revista complutense de educación. 23 (1). pp. 11-22.

http://revistas.ucm.es/index.php/RCED/article/view/ 39099/37712 Fecha de consulta, 12.06.2014.

Mitra, Sugata; Rana, Vivek (2001). Children and the Internet: experiments with minimally invasive education in India, The British Journal of Educational Technology 32 (2), pp. 221-232. http://dx.doi.org/10.1111/1467-8535.00192

Ponte, Manuel (2011). La rebelión de los Lurkers, participation inequality. Blog de Manuel Ponte. http://manuelponte.com/2011/11/10/la-rebelion-delos-lukers-participation-inequality Fecha de consulta, 12.06.2014.

Preece, Jenny; Nonnecke, Blair; Andrews, Dorine (2004). The top 5 reasons for lurking: Improving community experiences for everyone. Computers in Human Behavior, 20 (2), 201-223. http://dx.doi.org/10.1016/j.chb.2003.10.015

Prensky, Marc (2001). Digital Natives, Digital Immigrants. On the Horizon, October, 9 (5). 
Ramsden, Paul (2003). Learning to Teach in Higher Education. Londres: RoutledgeFalmer.

Reinoso, Raul (2013). Módulo 1: Introducción a la realidad aumentada. [Presentación slideshare]. Escuela virtual de verano 2013 espiral (eve13). http://www.slideshare.net/tecnotic Fecha de consulta, 12.06.2014.

Sharples, Mike; McAndrew, Patrick; Weller, Martin; Ferguson, Rebecca; FitzGerald, Elizabeth; Hirst, Tony; Gaved, Mark (2013). Innovating Pedagogy 2013: Open University Innovation Report 2. The Open University. Milton Keynes: The Open University.

White, David; Le Cornu, Alison (2011). Visitors and Residents: A New Typology for Online Engagement. First Monday, 16 (9). http://firstmonday.org/htbin/cgiwrap/bin/ojs/index.php/fm/article/view/3171/3049 Fecha de consulta, 12.06.2014.

\section{| Cita recomendada de este artículo}

Castañeda Quintero, Linda; Gutiérrez Porlán, Isabel y Román García, María del Mar (2014). Enriqueciendo la realidad: realidad aumentada con estudiantes de Educación Social. @tic. revista d'innovació educativa. ( $\left.n^{\circ} 12\right)$. URL. Fecha de consulta, dd/mm/aaaa. 